\title{
Application of SARIMA Model on Money Supply
}

\author{
Shichang Shen, Shan Chen \\ School of Mathematics and Statistics, Qinghai Nationalities University, Xining, China \\ Email: 13909785766@163.com
}

How to cite this paper: Shen, S.C. and Chen, S. (2017) Application of SARIMA Model on Money Supply. Open Journal of Statistics, 7, 112-121.

https://doi.org/10.4236/ojs.2017.71009

Received: January 9, 2017

Accepted: February 25, 2017

Published: February 28, 2017

Copyright $\odot 2017$ by authors and Scientific Research Publishing Inc. This work is licensed under the Creative Commons Attribution International License (CC BY 4.0).

http://creativecommons.org/licenses/by/4.0/

\begin{abstract}
In the paper, the data of the narrow money supply of China from January 2005 to March 2016 as sample, $\operatorname{SARIMA}(4,1,4)(0,1,1)^{12}$ model is established by using Eviews6.0. Upon inspection, the model has good fitting effect $(\mathrm{MAPE}=1.09)$ and high prediction accuracy. According to the results of the model, the paper forecasts the development trend of the narrow money supply of China and puts forward some suggestions to provide reference for monetary policy of China.
\end{abstract}

\section{Keywords}

SARIMA Model, Money Supply, Forecast

\section{Introduction}

As the intermediate target of monetary policy, money supply is one of the important means of macroeconomic regulation. It includes narrow money supply and broad money supply. The difference between the two is that the former does not include guasi-money. For a country or a region, money supply will affect its inflation rate. Generally, the central bank will take the total money supply as the main means of regulation to keep the currency stable. In addition, money supply is also crucial to the development of capital market. Changes in money supply will lead to the changes of market interest rates, which have an effect on the investment costs and profits of listed companies and ultimately make the company stock change. Chen Riqing and Wang Tongtong (2011) [1] analyzed the nonlinear effects of the money supply on Chinese insurance market by building the Markov regime switching model. Gu Liubao and Chen Bofei (2013) [2], by building the VAR model, used impulse response function and variance decomposition to analyze the dynamic affection of the changes of money supply and interest rate on the price of real estate market. Zhang Xiuli (2011) [3] analyzed the correlation between money supply and stock price. In fact, scholars had less 
research on the trend of narrow money supply in the past. But narrow money supply is central bank's key regulatory object because of its strong liquidity. Therefore, it is of great significance to predict its development trend. In the paper, based on the data of the narrow money supply of China from January 2005 to March 2016 as sample, SARIMA (Seasonal Auto Regressive Integrated Moving Average) model is established by using Eviews6.0. According to the results of the model, we predicted the development trend of the narrow money supply of China and put forward some suggestions to provide reference for monetary policy of China.

\section{Model Building and Data Illustration}

This paper takes the narrow money supply of China from January 2015 to March 2016 as sample, which denoted as $Y_{t}$ (Unit: billion yuan). The prediction model is established by using Eviews6.0. [4] and the narrow money supply from April to September 2016 are reserved to test the effect of the model. The data is obtained from People's Republic of China Bureau of Statistics Database (http://data.stats.gov.cn/).

\subsection{Data Preprocessing}

The line chart (see Figure 1) of $Y_{t}$ shows that the narrow money supply has a certain trend. It shows that the sequence is a non-stationary series. In order to reduce the fluctuation of the series and eliminate the heteroscedasticity that may exist in the data, the natural logarithm of $Y_{t}$ is taken as $\operatorname{Ln} Y_{t}$. To confirm the stationarity of $\operatorname{Ln} Y_{t}$, the ADF test is performed, and the result is as follow (see Table 1).

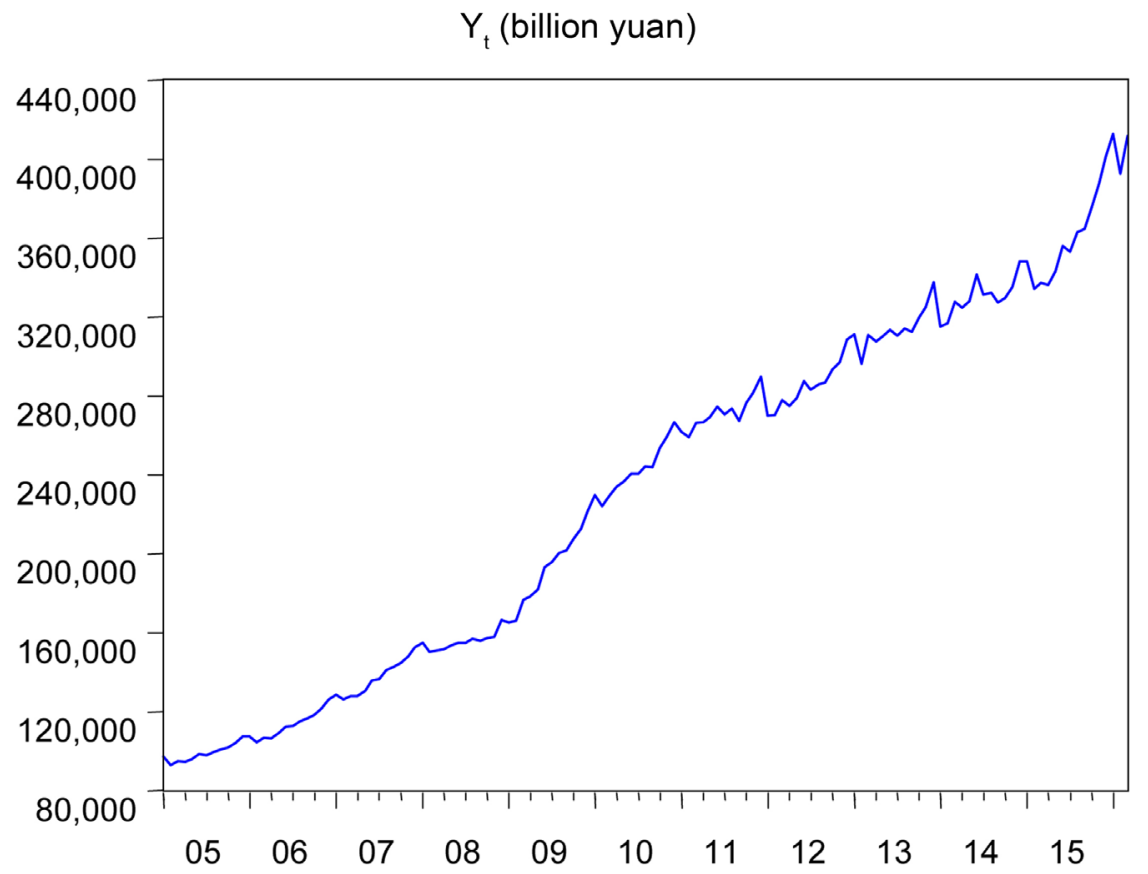

Figure 1. Line chart. 
Table 1. ADF test about $\operatorname{Ln} Y_{t}$.

\begin{tabular}{cccc}
\hline & & $t$-Statistic & Prob. \\
\hline Augmented Dickey-Fuller test statistic & -0.964622 & 0.7645 \\
Test critical values: & \% level & -3.479656 & \\
& $5 \%$ level & -2.883073 & \\
$10 \%$ level & -2.578331 & \\
\hline
\end{tabular}

According to the Table 1 , the value of $T$ statistic is -0.964622 , which is relatively bigger compared with the critical values at $1 \%, 5 \%$ and $10 \%$ confidence level. It means that $\operatorname{Ln} Y_{t}$ has a unit root. So it is a non-stationary series. In order to make it stationary, it is processed by the first order difference. The processed series is marked as $\nabla \operatorname{Ln} Y_{t}$. Its autocorrelation graph and partial autocorrelation graph are shown in Figure 2. We can see that the trend of $\nabla \operatorname{Ln} Y_{t}$ has been eliminated by Figure 2. But when $k=122,436$, the autocorrelation coefficient and partial autocorrelation coefficient of $\nabla \operatorname{Ln} Y_{t}$ have significant difference compared with 0 . This shows that it is seasonal time series. After the first order seasonal difference for the sequence, the new series is marked as $W_{t}\left(W_{t}=\nabla \nabla_{12} \ln Y_{t}\right)$.

The ADF test of $W_{t}$ is taken to judge whether the processed series $W_{t}$, is stationary or not. And the result of the ADF test is shown in Table 2. From the result, we can know that the value of $T$ statistic is -39.92772 , which is smaller compared with the critical values at $1 \%, 5 \%$ and $10 \%$ confidence level. In addition, the $P$ value is almost 0 , so the original hypothesis is rejected and there is no unit root in $W_{t}$. Therefore, it is a stationary series and its autocorrelation graph and partial autocorrelation graph are shown in Figure 3.

\subsection{Model Recognition}

Box-Jenkins method is an important method to identify SARIMA model [5] [6]. It identifies the model and confirms the order of the model by autocorrelation function and partial autocorrelation function of the sample. The autocorrelation graph and partial autocorrelation graph of $W_{t}$ are shown in Figure 3. We can observe that $\rho_{k}$ (autocorrelation function of the sample) in AC column have significant difference compared with 0 when $k=10,11$ and $\varphi_{k k}$ (partial autocorrelation function of the sample) in PAC column also have significant difference compared with 0 when $k=7,8$ from Figure 3 . So the autocorrelation and partial autocorrelation function are both tailing. In addition, when $k=12, \rho_{k}$ has significant difference compared with 0 and $\varphi_{k k}$ has not significant difference compared with 0 . So the seasonal autoregressive order of the model is 0 and the seasonal moving average order of the model is 1 . That is, $P=0, Q=1$. At the same time, according to the identification principle of ARMA model [5], the order of model calculated by $\rho_{k}$ and $\varphi_{k k}$ is as follows. When $k=1,2,3,4,5$ or 6 the proportion of $\rho_{k+1}, \rho_{k+2}, \cdots, \rho_{k+M}$ satisfying 


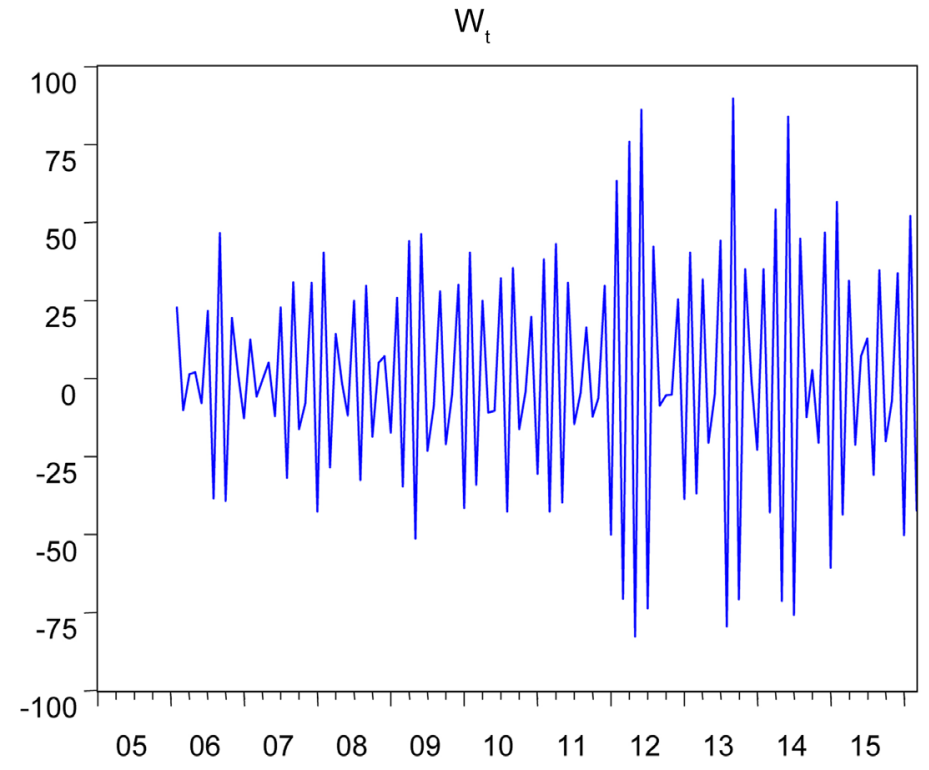

Figure 2. Line chart about $W_{t}$.

\begin{tabular}{|c|c|c|c|c|c|c|c|c|}
\hline \multicolumn{2}{|c|}{ Autocorrelation } & \multicolumn{3}{|c|}{ Partial Correlation } & $A C$ & PAC & Q-Stat & Prob \\
\hline [ & 1 & ᄃ & 1 & 1 & -0.899 & -0.899 & 101.08 & 0.000 \\
\hline I & & & 1 & 2 & 0.652 & -0.818 & 154.64 & 0.000 \\
\hline$\square$ & 1 & $\square$ & 1 & 3 & -0.356 & -0.409 & 170.74 & 0.000 \\
\hline I & וב & 1 & 1 & 4 & 0.102 & 0.054 & 172.08 & 0.000 \\
\hline I & 1 & 1 & $\square$ & 5 & 0.064 & 0.165 & 172.61 & 0.000 \\
\hline 吅 & 1 & 1 & 1 & 6 & -0.141 & 0.036 & 175.20 & 0.000 \\
\hline I & ا & $\square$ & I & 7 & 0.140 & -0.233 & 177.78 & 0.000 \\
\hline 14 & 1 & 1 & $\square$ & 8 & -0.070 & 0.197 & 178.43 & 0.000 \\
\hline 1 & I & 10 & 1 & 9 & -0.056 & -0.038 & 178.85 & 0.000 \\
\hline I & $\sqsupset$ & 1 & 1 & 10 & 0.204 & -0.090 & 184.48 & 0.000 \\
\hline$\square$ & 1 & 1 & $\square^{\prime}$ & 11 & -0.321 & 0.134 & 198.50 & 0.000 \\
\hline 1 & $\square$ & 1 & 1 & 12 & 0.352 & -0.101 & 215.57 & 0.000 \\
\hline$\square$ & 1 & 1 & 1 & 13 & -0.280 & 0.024 & 226.45 & 0.000 \\
\hline
\end{tabular}

Figure 3. Correlogram graph about $W_{t}$.

Table 2. ADF test about $W_{t}$.

\begin{tabular}{cccc}
\hline & & $t$-Statistic & Prob. \\
\hline Augmented Dickey-Fuller test statistic & -39.92772 & 0.0000 \\
Test critical values: & 1\% level & -2.584375 & \\
& $5 \%$ level & -1.943516 & \\
& $10 \%$ level & -1.614956 & \\
\hline
\end{tabular}

$\left|\rho_{k+i}\right| \leq\left[\frac{1}{N}\left(1+2 \sum_{l=1}^{m} \hat{\rho}_{l}^{2}\right)\right]^{\frac{1}{2}}$ where $i=1,2 \cdots M, \quad M=[\sqrt{N}]=[\sqrt{122}]=11$ and $N$ is the sample size of $W_{t}$, is $54.55 \%$ or $63.64 \%$ which are all less than $68.3 \%$. And the proportion of $\rho_{k+1}, \rho_{k+2}, \cdots, \rho_{k+M}$ satisfying 
$\left|\rho_{k+i}\right| \leq 2\left[\frac{1}{N}\left(1+2 \sum_{l=1}^{m} \hat{\rho}_{l}^{2}\right)\right]^{\frac{1}{2}}(i=1,2 \cdots M)$ is $63.64 \%, 81.82 \%$ or $90.91 \%$, which are all less than $95.5 \%$. So $\rho_{k}$ is tailing. When $k=1,2,3,4,5$ or 6 the proportion of $\varphi_{k+1, k+1}, \varphi_{k+2, k+2}, \cdots \varphi_{k+M, k+M}$ satisfying $\left|\varphi_{k k}\right|>\frac{1}{\sqrt{N}}$ is greater than $31.7 \%$ and the proportion of $\rho_{k+1}, \rho_{k+2}, \cdots, \rho_{k+M}$ satisfying $\left|\varphi_{k k}\right|>\frac{2}{\sqrt{N}}$ is greater than $4.5 \%$. So $\varphi_{k k}$ is tailing. In summary, autocorrelation and partial autocorrelation function are both tailing. This is consistent with the result of subjective recognition from the correlogram graph of $W_{t}$ series. So $\operatorname{SARIMA}(p, 1, q)(0,1,1)^{12}$ ( $p \neq 0$ and $q \neq 0$ ) model should be established.

The $p$ and $q$ in $\operatorname{SARIMA}(p, 1, q)(0,1,1)^{12}$ model can't be determined directly. Because the order of SARIMA model should not be high, $p$ can be chosen as 5 and $q$ can be chosen as 4 preliminarily by Figure 3. But most of parameters in SARIMA $(5,1,4)(0,1,1)^{12}$ model don't pass $t$-test. We can reduce the model's order properly to seek the optimal model. Based on the above conclusions and Figure 3, the possible models are $\operatorname{SARIMA}(4,1,4)(0,1,1)^{12}$, $\operatorname{SARIMA}(4,1,3)(0,1,1)^{12}$ and $\operatorname{SARIMA}(3,1,3)(0,1,1)^{12}$.

\subsection{Construction of Model}

The adjusted $R^{2}$, AIC, and SC criteria are considerable important factors when we choose a SARIMA model. Generally, we consider that the model making the value of AIC and SC function smaller is better. From Table 3, we can find that $\operatorname{SARIMA}(4,1,4)(0,1,1)^{12}$ and $\operatorname{SARIMA}(3,1,3)(0,1,1)^{12}$ model excel SARIMA $(4,1,3)(0,1,1)^{12}$ model. Compared with adjusted $R^{2}$, the bigger value shows the better fitting effect of the model. The value of adjusted $R^{2}$ about SARIMA $(4,1,4)(0,1,1)^{12}$ model is biggest compared with the other models. In summary, SARIMA $(4,1,4)(0,1,1)^{12}$ model should be chosen as the most suitable prediction model. And the reciprocal roots of the lag polynomial about the model are all less than 1 , which satisfies the requirement of process stabilization. The results of parameters estimation about $\operatorname{SARIMA}(4,1,4)(0,1,1)^{12}$ model are shown in Table 4.

\subsection{The Test of Model Residual Series}

According to the above we initially judge $\operatorname{SARIMA}(4,1,4)(0,1,1)^{12}$ as the appropriate model, and we should also test the applicability of the model. This is

Table 3. Models comparison.

\begin{tabular}{ccccc}
\hline Models & Inverted Roots & Adjusted $R^{2}$ & AIC & SC \\
\hline $\operatorname{SARIMA}(4,1,4)(0,1,1)^{12}$ & $\left|\lambda_{i}\right|<1$ & 0.564752 & -5.470924 & -5.259601 \\
$\operatorname{SARIMA}(4,1,3)(0,1,1)^{12}$ & $\left|\lambda_{i}\right|<1$ & 0.523222 & -5.387604 & -5.199761 \\
$\operatorname{SARIMA}(3,1,3)(0,1,1)^{12}$ & $\left|\lambda_{i}\right|<1$ & 0.547155 & -5.453272 & -5.289795 \\
\hline
\end{tabular}


Table 4. Parameters estimation of $\operatorname{SARIMA}(4,1,4)(0,1,1)^{12}$ model.

\begin{tabular}{ccccc}
\hline Variable & Coefficient & Std. Error & $t$-Statistic & Prob. \\
\hline AR(1) & 0.124123 & 0.068902 & 1.801455 & 0.0744 \\
AR(2) & 0.475486 & 0.069742 & 6.817791 & 0.0000 \\
AR(3) & 0.479315 & 0.061410 & 7.805100 & 0.0000 \\
AR(4) & -0.564442 & 0.063236 & -8.925930 & 0.0000 \\
MA(1) & -0.319742 & 0.018708 & -17.09109 & 0.0000 \\
MA(2) & -0.536473 & 0.030100 & -17.82320 & 0.0000 \\
MA(3) & -0.318432 & 0.019858 & -16.03577 & 0.0000 \\
MA(4) & 0.968683 & 0.011388 & 85.05812 & 0.0000 \\
SMA(12) & -0.887606 & 0.022645 & -39.19585 & 0.0000 \\
R-squared & 0.594513 & Mean dependent var & 0.000578 \\
Adjusted R-squared & 0.564752 & S.D. dependent var & 0.022935 \\
S.E. of regression & 0.015131 & Akaike info criterion & -5.470924 \\
Sum squared resid & 0.024956 & Schwarz criterion & -5.259601 \\
Log likelihood & 331.7845 & Hannan-Quinn criter. & -5.385120 \\
Durbin-Watson stat & 2.061025 & & & -0.99 \\
Inverted AR Roots & $0.74-0.29 \mathrm{i}$ & $0.74+0.29 \mathrm{i}$ & $-0.68+0.66 \mathrm{i}$ & $-0.68-0.66 \mathrm{i}$ \\
Inverted MA Roots & 0.99 & $0.88-0.47 \mathrm{i}$ & $0.88+0.47 \mathrm{i}$ & $0.86-0.50 \mathrm{i}$ \\
& $0.86+0.50 \mathrm{i}$ & $0.50-0.86 \mathrm{i}$ & $0.50+0.86 \mathrm{i}$ & $0.00+0.99 \mathrm{i}$ \\
& $-0.00-0.99 \mathrm{i}$ & $-0.50+0.86 \mathrm{i}$ & $-0.50-0.86 \mathrm{i}$ & $-0.72+0.69 \mathrm{i}$ \\
& $-0.72-0.69 \mathrm{i}$ & $-0.86+0.50 \mathrm{i}$ & $-0.86-0.50 \mathrm{i}$ & -0.99 \\
\hline
\end{tabular}

an independence test of model residual $a_{t}$. It is used for judging whether this model is suitable for describing the time series and it is necessary to further improve the model or not. The results of the Chi-square test are as follows (see Figure 4). The sample size of the residual series is 120 . So its maximum lag period can be taken as $10([\sqrt{120}])$. The $P$ value of the corresponding $Q$ statistic is 0.904 , so the original hypothesis that the residual series is independent can't be rejected. This indicates that the residual series of the model is purely random. That is to say, it is a white noise series.

\section{The Prediction Based on the Model}

The model is reasonable through the above test. It can be used for short-time prediction. In order to test the prediction accuracy of the model, firstly we use the mean absolute percentage error (MAPE) and Theil inequality coefficient (TIC) to test the fitting effect of the model. Among them,

$$
\begin{gathered}
\text { MAPE }=\frac{100}{n} \sum_{i=1}^{n}\left|\frac{y_{i}-\hat{y}_{i}}{y_{i}}\right| \\
\text { TIC }=\frac{\sqrt{\frac{1}{n} \sum_{i=1}^{n}\left(y_{i}-\hat{y}_{i}\right)^{2}}}{\sqrt{\frac{1}{n} \sum_{i=1}^{n} y_{i}^{2}}+\sqrt{\frac{1}{n} \sum_{i=1}^{n} \hat{y}_{i}^{2}}}
\end{gathered}
$$




\begin{tabular}{|c|c|c|c|c|c|c|}
\hline Autocorrelation & Partial Correlation & & $A C$ & PAC & Q-Stat & Prob \\
\hline 101 & 10 & 1 & -0.040 & -0.040 & 0.1909 & 0.662 \\
\hline 1 1 & $1 \mathrm{~b}$ & 2 & 0.061 & 0.059 & 0.6384 & 0.727 \\
\hline 1 1 1 & I I 1 & 3 & 0.060 & 0.064 & 1.0751 & 0.783 \\
\hline \begin{tabular}{l|l}
1 & 1
\end{tabular} & \begin{tabular}{l|l}
1 & 1
\end{tabular} & 4 & 0.000 & 0.001 & 1.0751 & 0.898 \\
\hline 1 1 & I 1 & 5 & -0.085 & -0.093 & 1.9722 & 0.853 \\
\hline 11 & 111 & 6 & -0.002 & -0.013 & 1.9726 & 0.922 \\
\hline ון ו & ו & 7 & 0.119 & 0.132 & 3.7871 & 0.804 \\
\hline 11 & \begin{tabular}{l|l}
1 & 1
\end{tabular} & 8 & -0.015 & 0.008 & 3.8159 & 0.873 \\
\hline 10 1 & 地 1 & 9 & -0.087 & -0.109 & 4.7975 & 0.852 \\
\hline $1 \mid 1$ & 11 & 10 & 0.010 & -0.024 & 4.8098 & 0.904 \\
\hline $1 \mid 1$ & 1 1 & 11 & 0.014 & 0.033 & 4.8368 & 0.939 \\
\hline I & Id I & 12 & -0.136 & -0.101 & 7.3185 & 0.836 \\
\hline 101 & 101 & 13 & 0.045 & 0.030 & 7.5887 & 0.869 \\
\hline
\end{tabular}

Figure 4. Correlogram of $\operatorname{SARIMA}(4,1,4)(0,1,1)^{12}$ model residual.

The static predicted values the narrow money supply of China from January 2005 to March 2016 gained by $\operatorname{SARIMA}(4,1,4)(0,1,1)^{12}$ model. Then we compare them with the real values (see Figure 5) and calculate the values of MAPE and TIC. It can be seen from Figure 5 that the coincidence degree is high between the predicted value curve (YF) and the real value curve (Y) in sample. Their trends are basically the same and all residuals fluctuate near 0 . And the value of MAPE is 1.09 less than 5. It shows that the prediction accuracy of the model is high. Besides, the value of TIC is 0.00768 . This means that there are slight differences between the predicted values and real values in sample.

At the same time, we use the model to forecast the narrow money supply of China from April to September 2016 and compare the forecast values with the real values. The dynamic predicted values and relative errors are as follows (see Table 5).

From Table 5, we can know that the average relative error of the model is $1.27 \%$. This shows the difference between the predicted values and the real values out of sample are slight. That is, the prediction accuracy of the model is high.

The above analysis shows that $\operatorname{SARIMA}(4,1,4)(0,1,1)^{12}$ model is appropriate for forecasting narrow money supply. We forecast the narrow money supply of China from October 2016 to February 2018 (see Table 6). In order to observe and analyze the change regularity more intuitively, the forecast values of future money supply are plotted with the previous values (Figure 6). The narrow money supply of China is going to grow in the next 15 months by Figure 6 .

\section{Conclusions and Suggestions}

1) SARIMA $(4,1,4)(0,1,1)^{12}$ model, based on the narrow money supply of China from January 2005 to March 2016 as sample, eventually is established after comparative analysis. Its numerical value of mean absolute percentage error (MAPE) is 1.09 and the value of theil inequality coefficient (TIC) is 0.00768 . The data from April 2016 to September 2016 are predicted, and the predicted values 


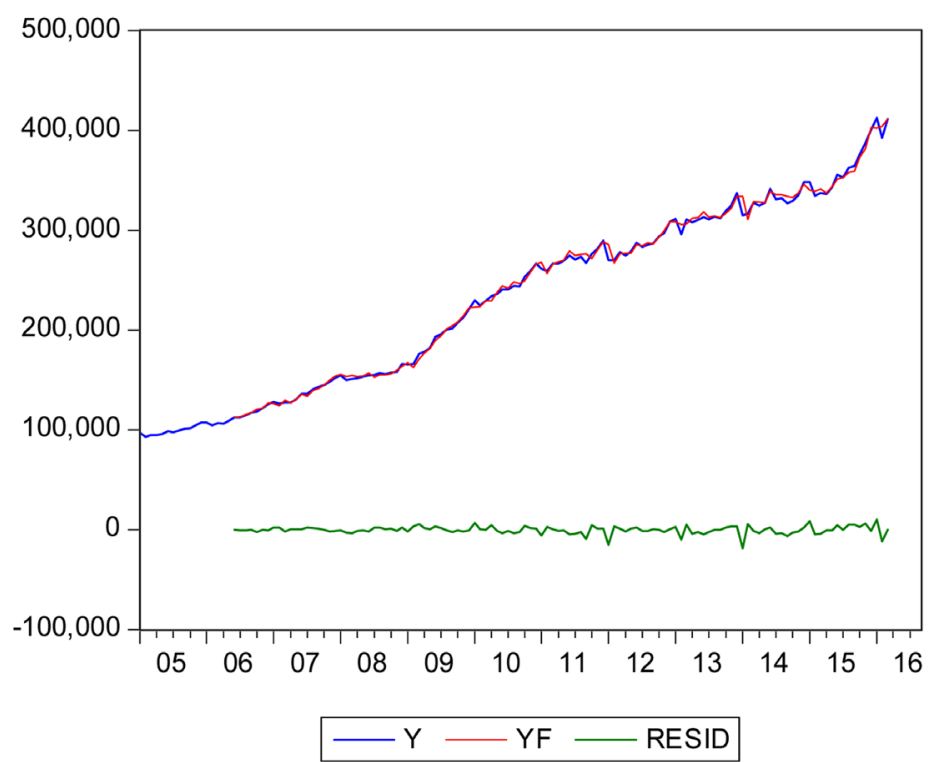

Figure 5. Comparison between the real values and predicted values in sample.

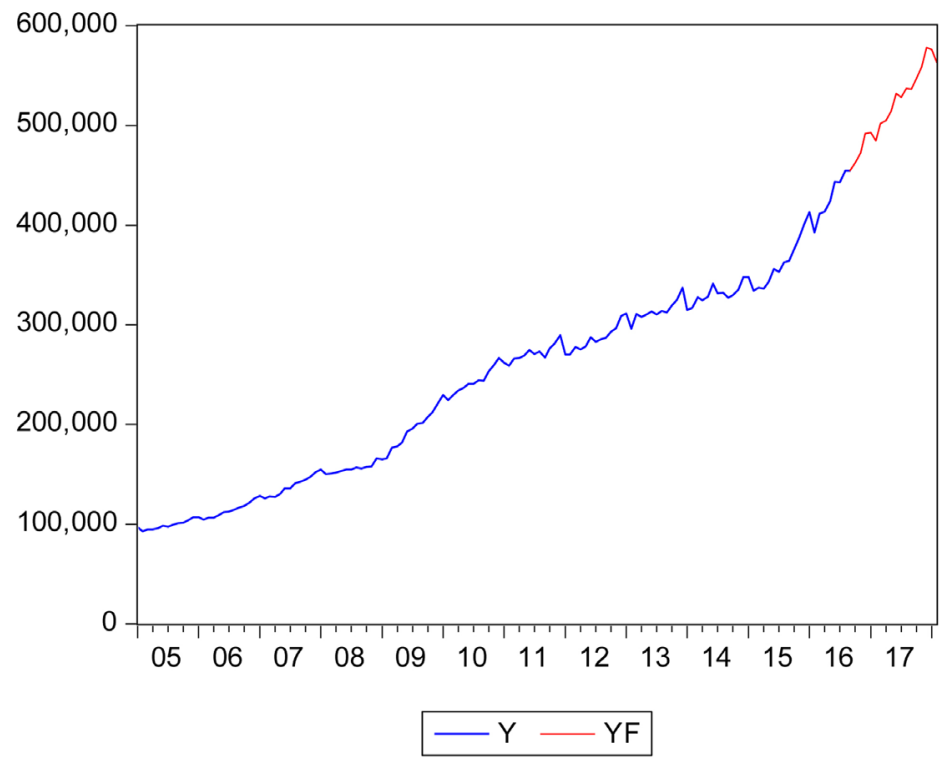

Figure 6. The graph of early values $(\mathrm{Y})$ and predicted values about future (YF).

Table 5. Prediction error of $\operatorname{SARIMA}(4,1,4)(0,1,1)^{12}$ model.

\begin{tabular}{cccc}
\hline Time & Real values & Dynamic predicted values & Relative errors \\
\hline 2016.04 & $413,504.84$ & $416,171.96$ & $0.65 \%$ \\
2016.05 & $424,250.70$ & $426,252.46$ & $0.47 \%$ \\
2016.06 & $443,643.70$ & $441,477.73$ & $0.49 \%$ \\
2016.07 & $442,934.43$ & $437,336.70$ & $1.26 \%$ \\
2016.08 & $454,543.60$ & $444,481.38$ & $2.21 \%$ \\
2016.09 & $454,340.25$ & $442,756.64$ & $2.55 \%$ \\
\hline
\end{tabular}


Table 6. Forecast the narrow money supply of China.

\begin{tabular}{cccc}
\hline Time & Predicted values & Time & Predicted values \\
\hline 2016.10 & $462,084.98$ & 2017.07 & $528,081.20$ \\
2016.11 & $472,496.81$ & 2017.08 & $536,912.25$ \\
2016.12 & $491,533.81$ & 2017.09 & $536,505.71$ \\
2017.01 & $492,726.39$ & 2017.10 & $547,061.04$ \\
2017.02 & $484,342.35$ & 2017.11 & $558,134.97$ \\
2017.03 & $502,012.32$ & 2017.12 & $578,256.43$ \\
2017.04 & $504,697.96$ & 2018.01 & $575,961.67$ \\
2017.05 & $514,090.71$ & 2018.02 & $563,187.20$ \\
2017.06 & $531,929.28$ & & \\
\hline
\end{tabular}

are compared with the reserved real values. The result shows that the forecasting precision is $98.73 \%$. These results show that the model has good fitting effect and high prediction accuracy.

2) The narrow money supply of China from October 2016 to February 2018, which is forecasted based on $\operatorname{SARIMA}(4,1,4)(0,1,1)^{12}$ model, is compared with the historical data. The results are as follows. In the next fifteen months, the overall trend is the same with the last two years', which shows the same proportion of growth. While compared with the money supply before 2015, it shows a substantial growth.

According to the above conclusions, this paper puts forward the following suggestions for the formulation of China's monetary policy: 1) In the next year, the money supply will continue to grow. The stock demand is expected to increase which would stimulate the stock prices. It can be appropriate to guide funds into the stock market, stimulate consumption and promote economic growth. 2) With the money supply growing constantly, the central bank should be alert to the risks and improve the control for it. It is necessary to implement a moderately tight monetary policy to avoid the emergence of rapid inflation and hyperinflation phenomenon. 3) The coordination between monetary policy and other economic policies should be strengthened to achieve the balance between the demand and supply.

\section{Fund}

This work is supported by the National Natural Science Foundation of China (No. 11561056) and Natural Science Foundation of Qinghai (No. 2016-ZJ-914).

\section{References}

[1] Chen, R.Q. and Wang, T.T. (2016) The Nonlinear Effects of the Money Supply on Chinese Insurance Market. Insurance Studies, No. 7, 55-67.

[2] Gu, L.B. and Chen, B.F. (2013) The Analysis of Policy's Affections on First-and Second-Tier Cities' Real Estate Markets. Journal of Hebei University of Economics and Business, 34, 15-18.

[3] Zhang, X.L. (2012) Empirical Study on the Relationship of Money supply and Stock 
Market Price. On Economic Problems, No. 10, 89-92.

[4] Yi, D.H. (2008) Data Analysis and Application of Eviews. China Renmin University Press, Beijing.

[5] Wang, Z.L. (2010) Applied Time Series Analysis. China Statistics Press, Beijing.

[6] The People's Bank of China, Statistics and Analysis Department (2006) Seasonal Adjustment on X-12-ARIMA-Theory and Method. China Financial Publishing House, Beijing.

Submit or recommend next manuscript to SCIRP and we will provide best service for you:

Accepting pre-submission inquiries through Email, Facebook, LinkedIn, Twitter, etc. A wide selection of journals (inclusive of 9 subjects, more than 200 journals) Providing 24-hour high-quality service User-friendly online submission system Fair and swift peer-review system Efficient typesetting and proofreading procedure Display of the result of downloads and visits, as well as the number of cited articles Maximum dissemination of your research work

Submit your manuscript at: http://papersubmission.scirp.org/ Or contact ojs@scirp.org 